\title{
Analysis of MEN1 c.482G >A (p.Gly161Asp) mutation in a pedigree with familial multiple endocrine neoplasia type 1
}

\author{
YUANYUAN LUO ${ }^{1}$, YONGXIANG SUN ${ }^{2}$, XIAOFAN ZHU $^{1}$ and XIALIAN LI ${ }^{1}$ \\ ${ }^{1}$ Department of Endocrinology and Metabolism, Genetic and Prenatal Diagnosis Center, The First Affiliated Hospital of \\ Zhengzhou University, Zhengzhou, Henan 450052; ${ }^{2}$ Department of Endocrinology and Geriatrics, \\ The Medical Group of Zhengzhou First People's Hospital, Zhengzhou, Henan 450000, P.R. China
}

Received March 31, 2017; Accepted September 25, 2017

DOI: $10.3892 / \mathrm{mmr} .2017 .7749$

\begin{abstract}
Multiple endocrine neoplasia type 1 (MEN1) is an autosomal dominant disorder characterized by the development of neuroendocrine tumors, which in turn are caused by mutations in the MEN1 gene. In the present study, a case of a 46-year-old woman who was clinically diagnosed with MEN1 based on the presence of prolactinoma and bilateral parathyroid adenoma was reported. The patient's serum prolactin (PRL) levels were successfully controlled via bromocriptine therapy, and the serum levels of calcium and intact parathyroid hormone $(\mathrm{PTH})$ reduced one day following parathyroidectomy. Genetic testing revealed a missense mutation c. $482 \mathrm{G}>\mathrm{A}$ (p.Gly161Asp) in exon 3 of the MEN1 gene, and it led to the identification of two carriers in the pedigree (patient's elder sister and brother). Both of the carriers revealed to have high blood calcium, PTH and PRL. The mutation identified in this pedigree has never been reported in China. The sequence alignments and tertiary structure of menin protein were made by Polyphen2, SNPs3D, and SIFT, which were used to predict the function of mutant menin. Since the mutant menin may interfere with the menin-JunD or menin-Smad3 interactions, further investigations are necessary to explore the function of mutant protein. In view of that, identification of mutations and longtime follow-up are important for patients with a pedigree clearly indicating MEN1.
\end{abstract}

Correspondence to: Professor Xialian Li, Department of Endocrinology and Metabolism, Genetic and Prenatal Diagnosis Center, The First Affiliated Hospital of Zhengzhou University, 1 Eastern Jianshe Road, Zhengzhou, Henan 450052, P.R. China E-mail: xialianli@hotmail.com

Abbreviations: MEN1, multiple endocrine neoplasia type 1; BMI, body mass index; MRI, magnetic resonance imaging; CT, computed tomography; BMD, bone mineral density

Key words: multiple endocrine neoplasia type 1, MEN1 gene, missense mutation, mutant menin

\section{Introduction}

Multiple endocrine neoplasia type 1 (MEN1) is an autosomal dominant disorder characterized by the occurrence of tumors of the parathyroids, anterior pituitary and neuroendocrine tumors of the pancreas and duodenum. It is furthermore associated with germline mutations of the MEN1 tumor suppressor gene. Parathyroid tumors, which lead to hypercalcemia are the most common feature of MEN1 occurring in about 95\% of patients. Pancreatic islet cell tumors occur in approximately $40 \%$ of patients, while anterior pituitary tumors occur in around $30 \%$ of patients (1). The MEN1 gene, which was identified in 1997 by Chandrasekharappa et al (2), consists of 10 exons that encode the protein referred to as menin. A comprehensive review and analysis of 38 years of data related to 613 MEN1 mutations found that frameshift mutations represent the highest rate $(42 \%)$, while missense mutations show a frequency of $25.5 \%$. Nonsense mutations represent $14 \%$, splice-site mutations $10.5 \%$; in-frame del/ins $5.5 \%$ and gross deletions represent the remaining $2.5 \%$ (3). Furthermore, the most mutations resulted in the 2,9 and 10 exons, but thus far the genotype-phenotype correlation has not been established (4). Therefore, DNA testing for MEN1 gene is an established and useful tool for the diagnosis of MEN1. In the present study we report a familial MEN1 case with prolactinoma and parathyroid adenoma, and a missense mutation c. $482 \mathrm{G}>\mathrm{A}$ in exon 3 of MENl gene, which has been shown to change the 161st amino acid from glycine to aspartate.

\section{Case report}

A 46-year-old woman was admitted to our hospital because of malaise and gastrointestinal discomfort. For the past 6 years she has been receiving bromocriptine treatment for prolactinoma, and she had a month old fracture in the left leg. Her mother died of 'gastric cancer' 6 years ago, and her brother was diagnosed with multiple kidney calculus 4 years ago. The rest of the family history was noncontributory. Her body mass index (BMI) was $31.1 \mathrm{~kg} / \mathrm{m}^{2}$. The patient's initial laboratory examinations are listed in Table I. Pituitary magnetic resonance imaging (MRI) scanning showed an adenoma in the pituitary (Fig. 1A). Abdominal computed tomography (CT) revealed multiple small calculi in the left kidney (Fig. 1B), while bone 
Table I. Laboratory results of the proband.

\begin{tabular}{lcc}
\hline Variable & Laboratory data & Normal range \\
\hline PTH (ng/ml) & 426.6 & $15-65$ \\
Calcium (mmol/l) & 3.08 & $2.2-2.7$ \\
24-h urine Ca (mmol/day) & 8.9 & $2.5-7.5$ \\
Phosphate $(\mathrm{mmol} / \mathrm{l})$ & 0.68 & $0.81-1.9$ \\
PRL $(\mathrm{ng} / \mathrm{ml})$ & 35.7 & $5.18-26.53$ \\
GH $(\mathrm{ng} / \mathrm{ml})$ & 0.5 & $0.06-5$ \\
IGF-1 $(\mathrm{ng} / \mathrm{ml})$ & 166 & $94-252$ \\
HbA1c $(\%)$ & 5.1 & $4.0-6.5$ \\
ACTH $(8: 00 \mathrm{am})(\mathrm{pg} / \mathrm{ml})$ & 45.6 & $7.2-63.3$ \\
Cortisol $(8: 00 \mathrm{am})(\mathrm{ng} / \mathrm{ml})$ & 511 & $171-536$ \\
\hline
\end{tabular}

PTH, intact parathyroid hormone; Ca, calcium; PRL, prolactin; $\mathrm{GH}$, growth hormone; IGF-1, insulin-like growth factor 1; HbA1c, haemoglobin A1C; ACTH, adrenocorticotropic hormone.

mineral density showed severe osteoporosis (Hologic Inc., Waltham, MA, USA). Dual-phase ${ }^{99 m}$ Technetium-Sestamibi ( $\left.{ }^{99 \mathrm{~m}} \mathrm{Tc}-\mathrm{MIBI}\right)$ scintigraphy revealed a significant uptake in the parathyroid gland located in the inferior side of bilateral thyroid, which was suggestive of parathyroid adenoma (Fig. 1C). The blood calcium decreased gradually after using bisphosphonate and salmon calcitonin. The postoperative pathology confirmed the bilateral parathyroid adenoma (Fig. 1D), and on day after parathyroidectomy, the levels of serum calcium $(2.4 \mathrm{mmol} / \mathrm{l})$ and parathyroid hormone $(\mathrm{PTH})(92.2 \mathrm{ng} / \mathrm{ml})$ were immediately reduced.

DNA was extracted from peripheral blood and resected parathyroid tissue samples of the proband. The samples were taken from her father, two elder sisters, brother and son after they signed a written informed consent. Simultaneously, their serum calcium, PTH and prolactin (PRL) were tested. We found the mutation c.482G>A (p.Gly161Asp) in the third exon of MEN1 gene in both peripheral blood and resected parathyroid tissue of the proband (Fig. 2A). Patient's brother and one of the elder sisters revealed the same mutation (Fig. 2B), as well as high blood calcium, PTH and PRL. Other family members tested normal, in both gene testing and related laboratory examination (Fig. 2C and D). The identified mutation has previously been reported (5); nevertheless previous studies did not clearly illustrate pathogenicity of this mutation and the function of the mutant protein. Polyphen2, SNPs3D and SIFT were used to predict the function of the 161st amino acid substitute from glycine to aspartate. Polyphen2 predicted result score was 1.00 (i.e., score closer to 1.00 was interpreted as the greater mutation damage; score closer to 0 was interpreted as the smaller damage); SNPs3D predicted result score was -1.97 (positive score was interpreted as harmless; negative score was interpreted as harmful); SIFT predicted result score was $0.00(<0.05$ was interpreted as having the ability to affect protein function). All the obtained results revealed that mutation may be harmful for the menin protein. Gene sequencing was performed by Sangon Biotech Co., Ltd. (Shanghai, China). The seqman of DNAstar package was used for alignment of sequenced and normal genes. The name of mutation
A
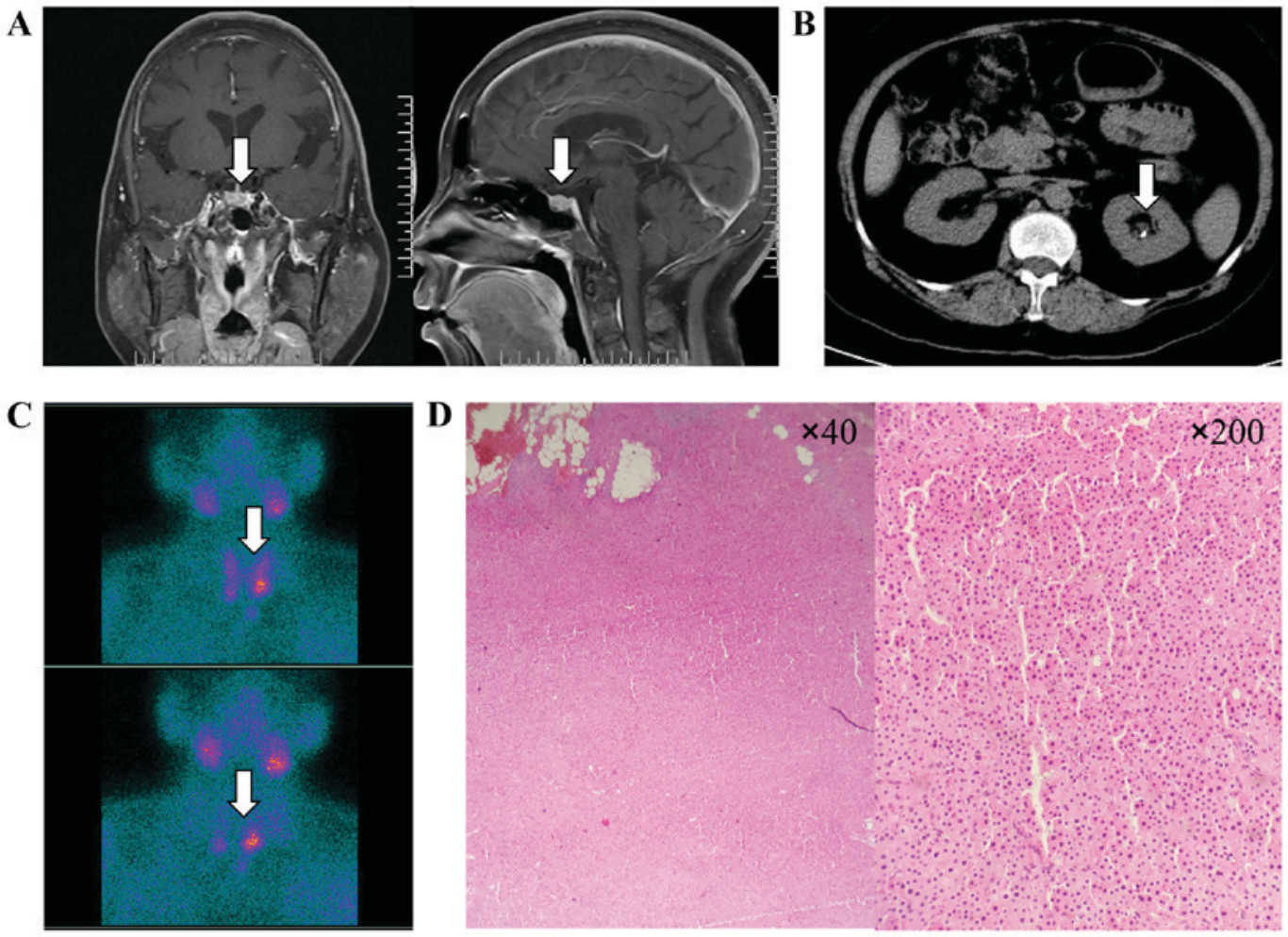

D

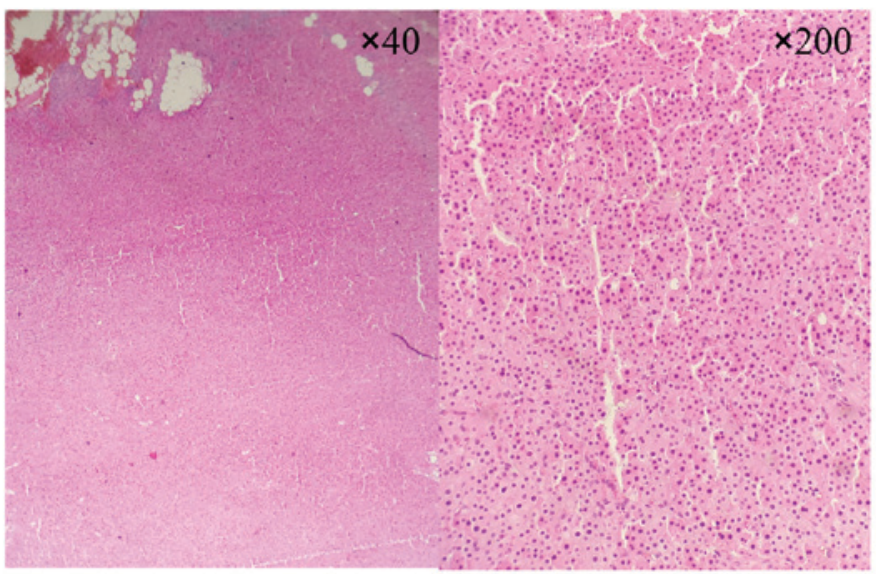

Figure 1. Real-time imaging and pathology examination of the proband. (A) Pituitary MRI showed adenoma in the pituitary. (B) Abdominal CT revealed multiple small calculi in the left kidney. (C) At early and late phase, dual-phase ${ }^{99 \mathrm{~m}}$ Tc-MIBI scintigraphy revealed a significant uptake in the parathyroid gland located in the both inferior thyroid (D) Postoperative pathology confirmed the bilateral parathyroid adenoma (H\&E staining; x40 and x200). MRI, magnetic resonance imaging; CT, computed tomography; ${ }^{99 \mathrm{~m}} \mathrm{Tc}-\mathrm{MIBI},{ }^{99 \mathrm{~m}}$ Technetium-Sestamibi. 


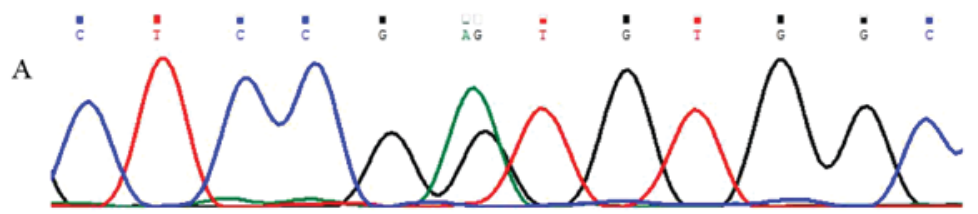

B

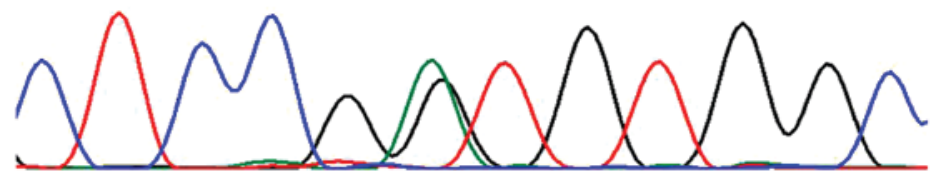

C

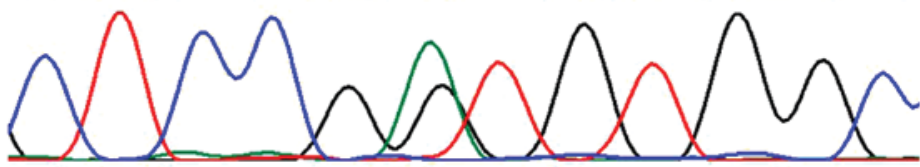

D

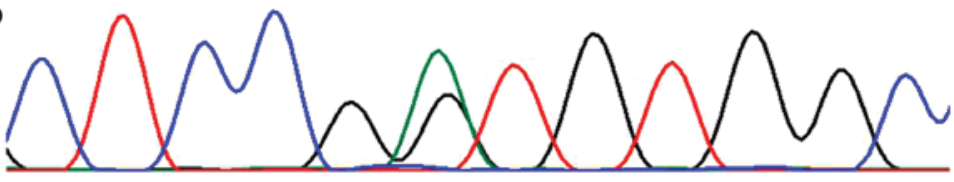

Figure 2. Genetic analysis in the pedigree. Heterozygous mutation c.482G $>$ A (p.Gly161Asp) in the third exon of $M E N 1$ gene in both peripheral blood (A) and resected parathyroid tissue (B) of the proband. The patient's elder sister (C) and brother (D) had the same mutation. MEN1, multiple endocrine neoplasia type 1.

I

II

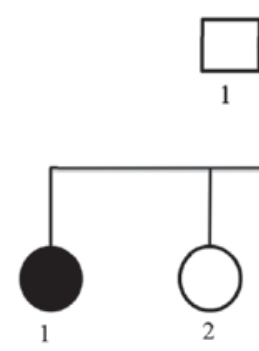

III

Figure 3. Pedigree diagram of the proband's family. Family members are indicated by generations (Roman numbers) and individuals (Arabic numbers). Circles indicate women and squares indicate men. Black symbol, mutation carriers and all heterozygous genotype, and white symbol, normal. Slash indicates a deceased individual at the time of the investigation, and the arrow indicates the presence of a proband.

\section{p.Gly161}

$\begin{array}{ll}\text { Q503J8_DANRE } & \text { TKLDSSGVIFAVVAACQVLGLKDVHL } \\ \text { MEN1_MOUSE } & \text { TKLDSSGVAFAVVGACQALGLRDVHL } \\ \text { MEN1_RAT } & \text { TKLDSSGVVAFAVVGACQALGLRDVHL } \\ \text { MEN1_BOVIN } & \text { TKLDSSGGVAFAVVGACQALGLRDVHL } \\ \text { MEN1_HUMAN } & \text { TKLDSSGVVAFAVVGACQALGLRDVHL } \\ \text { MEN1_CANLF } & \text { TKLDSSGVAFAVVGACQALGLRDVHL } \\ & * * * * * * * * * * * * * . * * * . * * *: * * * *\end{array}$

Figure 4. Amino acid sequence alignments of human menin and other homologous proteins. The figure represents partial alignment of menin sequences of human, mouse, rat, bovine, dog and zebrafish around the position of missence mutation (p.Gly161), which is denoted by a frame (the asterisk revealed highly conserved from different mammalia species). MEN1, multiple endocrine neoplasia type 1 .

referenced the cDNA sequence NM_00244.3 of Genbank.

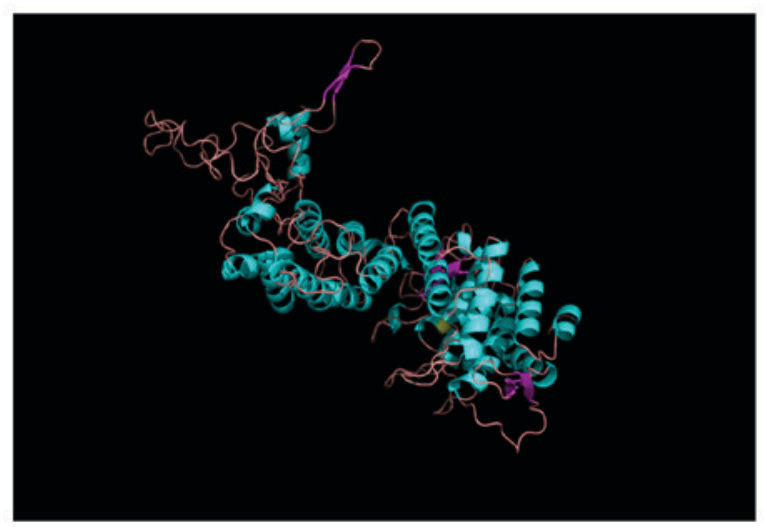

Figure 5. The tertiary structure of mutant menin was predicted using Swiss-model. Mutant amino acid p.Gly161Asp is presented in yellow.

The tertiary structure of menin protein was predicted using Swiss-model (6).

\section{Discussion}

The clinical diagnosis of MEN1 depends on the identification of neoplastic disease in at least two of the commonly affected organs, i.e., the parathyroid gland, endocrine pancreas, and anterior pituitary (7). In the present case, the diagnosis of MEN1 was demonstrated by prolactinoma and primary hyperparathyroidism with bilateral parathyroid adenoma. Genetic testing of the patient and family members revealed a missense mutation c.482G>A (p.Gly161 Asp) in patients and patient's elder sister and brother. The sequencing peak pattern revealed additional peak confirming the heterozygous mutation, and suggesting the patient's mother might had the same mutation in the pedigree, while other familiars tested normal (Fig. 3). Sequence alignments revealed that the glycine residues were highly conserved among menin proteins from different species (Fig. 4). 
The product of the MENI gene, menin, is a nuclear protein (8) and it is believed to function as a tumor suppressor having a number of potential roles in maintaining normal cell function. Some of the more researched menin functions indicated by direct interactions with many proteins and other molecules are: 3 JunD-interacting domains at codons 1-40, 139-242, and 323-428, Smad family at codons 40-278, and $477-610$, and 3 nuclear localization signals at codons 479-497, 546-572, and 588-608 (1). The missense mutation c.482G $>$ A (p.Gly161Asp) was identified at codon 161 which involved menin-JunD or menin-Smad3 interactions regions. Menin contains a deep pocket that can bind mixed-lineage leukemia 1 (MLL1 or KMT2A) protein or the transcription factor (TF) JunD, with opposite effects on gene transcription (9). In transcriptional regulation, menin has been shown to interact with the activating protein-1 (AP-1) and TF JunD (10), and to suppress Jun-mediated transcriptional activation (11). Thevenon et al (12) reported that patients with mutations affecting the JunD interacting domain had a higher risk of death secondary to a MEN1 tumor. In addition, members of the Smad family, Smad3 and the Smad 1/5 complex have been shown to be involved in the transforming growth factor- $\beta$ (TGF- $\beta$ ) (13) and the bone morphogenetic protein-2 (BMP-2) signaling pathways (14), respectively. For the tertiary structure, the mutation p.Gly161Asp changes the location of hydrogen bands (Fig. 5). The substitution of glycine, a neutral amino acid for aspartate, an acidic amino acid, might interfere with the menin-JunD or menin-Smad3 interactions. In the present case of the Gly161Asp mutation, the Polyphen2, SNPs3D and SIFT results, all supported the damage function of menin. Further studies are necessary to explore the function of mutant protein in vivo and in vitro.

Knudson's two-hit theory with a loss of heterozygosity (LOH) in the MENI gene is commonly used to explain tumorigenesis in the MEN1 patients (15). In the present study, the identified miscellaneous peak of the proband's resected parathyroid tissue confirmed a heterozygous missense mutation without $\mathrm{LOH}$, implying $\mathrm{LOH}$ might not be a unique condition. Luzi et al (16) found that microRNA24-1 (miR-24-1) has ability to bind to the untranslated region (3'UTR) of MEN1 mRNA. Also, the negative feedback-loop between the oncomir miR-24-1 and menin, existing in MEN1 parathyroid adenoma without $\mathrm{LOH}$, modulates the MEN1 tumorigenesis by mimicking the 'Knudson's second hit'.

In summary, we herein reported a case of MEN1 with a missense mutation c.482G $>$ A (p.Gly161Asp) of the MENI gene, which appeared to be responsible for MEN1. The proband and two family members had the same mutation and abnormal laboratory examinations. This suggests that identification of mutations might be very important for prompt diagnosis and monitoring of at-risk family members in MEN1 pedigrees (17).

\section{Acknowledgements}

This study was supported by the the Joint Project of Medical Science and Technology of Henan Province, China (grant no. 201201015).

\section{References}

1. Lemos MC and Thakker RV: Multiple endocrine neoplasia type 1 (MEN1): Analysis of 1336 mutations reported in the first decade following identification of the gene. Hum Mutat 29: 22-32, 2008.

2. Chandrasekharappa SC, Guru SC, Manickam P, Olufemi SE, Collins FS, Emmert-Buck MR, Debelenko LV, Zhuang Z, Lubensky IA, Liotta LA, et al: Positional cloning of the gene for multiple endocrine neoplasia-type 1. Science 276: 404-407, 1997.

3. Concolino P, Costella A and Capoluongo E: Multiple endocrine neoplasia type 1 (MEN1): An update of 208 new germline variants reported in the last nine years. Cancer Genet 209: 36-41, 2016.

4. Stewart C, Parente F, Piehl F, Farnebo F, Quincey D, Silins G, Bergman L, Carle GF, Lemmens I, Grimmond S, et al: Characterization of the mouse Men 1 gene and its expression during development. Oncogene 17: 2485-2493, 1998

5. Mutch MG, Dilley WG, Sanjurjo F, DeBenedetti MK, Doherty GM, Wells SA Jr, Goodfellow PJ and Lairmore TC: Germline mutations in the multiple endocrine neoplasia type 1 gene: Evidence for frequent splicing defects. Hum Mutat 13: 175-185, 1999.

6. Guex N, Peitsch MC and Schwede T: Automated comparative protein structure modeling with SWISS-MODEL and Swiss-PdbViewer: A historical perspective. Electrophoresis 30 (Suppl 1): S162-S173, 2009.

7. Thakker RV, Newey PJ, Walls GV, Bilezikian J, Dralle H, Ebeling PR, Melmed S, Sakurai A, Tonelli F and Brandi ML; Endocrine Society: Clinical practice guidelines for multiple endocrine neoplasia type 1 (MEN1). J Clin Endocrinol Metab 97: 2990-3011, 2012.

8. Guru SC, Goldsmith PK, Burns AL, Marx SJ, Spiegel AM, Collins FS and Chandrasekharappa SC: Menin, the product of the MEN1 gene, is a nuclear protein. Proc Natl Acad Sci USA 95: $1630-1634,1998$

9. Huang J, Gurung B, Wan B, Matkar S, Veniaminova NA, Wan K, Merchant JL, Hua X and Lei M: The same pocket in menin binds both MLL and JUND but has opposite effects on transcription. Nature 482: 542-546, 2012.

10. Agarwal SK, Guru SC, Heppner C, Erdos MR, Collins RM, Park SY, Saggar S, Chandrasekharappa SC, Collins FS, Spiegel AM, et al: Menin interacts with the AP1 transcription factor JunD and represses JunD-activated transcription. Cell 96: 143-152, 1999.

11. Pfarr CM, Mechta F, Spyrou G, Lallemand D, Carillo S and Yaniv M: Mouse JunD negatively regulates fibroblast growth and antagonizes transformation by ras. Cell 76: 747-760, 1994.

12. Thevenon J,Bourredjem A,Faivre L,Cardot-Bauters C,Calender A, Murat A, Giraud S, Niccoli P, Odou MF, Borson-Chazot F, et al: Higher risk of death among MEN1 patients with mutations in the JunD interacting domain: A Groupe d'Etude des Tumeurs Endocrines (GTE) cohort study. Hum Mol Genet 22: 1940-1948, 2013.

13. Kaji H, Canaff L, Lebrun JJ, Goltzman D and Hendy GN: Inactivation of menin, a Smad3-interacting protein, blocks transforming growth factor type beta signaling. Proc Natl Acad Sci USA 98: 3837-3842, 2001.

14. Sowa H, Kaji H, Canaff L, Hendy GN, Tsukamoto T, Yamaguchi T, Miyazono K, Sugimoto T and Chihara K: Inactivation of menin, the product of the multiple endocrine neoplasia type 1 gene, inhibits the commitment of multipotential mesenchymal stem cells into the osteoblast lineage. J Biol Chem 278: 21058-21069, 2003.

15. Knudson AG Jr: Mutation and cancer: Statistical study of retinoblastoma. Proc Natl Acad Sci USA 68: 820-823, 1971

16. Luzi E, Marini F, Giusti F, Galli G, Cavalli L and Brandi ML: The negative feedback-loop between the oncomir Mir-24-1 and menin modulates the Men 1 tumorigenesis by mimicking the 'Knudson's second hit'. PLoS One 7: e39767, 2012.

17. Falchetti A: Genetic screening for multiple endocrine neoplasia syndrome type 1 (MEN-1): When and how. F1000 Med Rep 2: pii: 14, 2010. 